\title{
Betrayal Trauma: Relationship to Physical Health, Psychological Distress, and a Written Disclosure Intervention
}

\author{
Jennifer J. Freyd, PhD \\ Bridget Klest, MA \\ Carolyn B. Allard, MS
}

\begin{abstract}
In the current study we sought, first, to distinguish associations with health arising from types of trauma as indicated by betrayal trauma theory (Freyd, 1996, 2001), and, second, to investigate the impact of disclosing a trauma history in survey form and/or writing essays about betrayal traumas. We recruited 99 community adults reporting at least 12 months of chronic medical illness or pain, 80 of whom completed all four sessions of this six-month longitudinal intervention study. Participants were randomly assigned to write about betrayal traumas or neutral events, and they were randomly assigned to complete an exten-
\end{abstract}

Jennifer J. Freyd, Bridget Klest, and Carolyn B. Allard are affiliated with the Department of Psychology, University of Oregon.

Address correspondence to: Jennifer J. Freyd, PhD, Department of Psychology, 1227 University of Oregon, Eugene, OR 97403-1227 (E-mail: jjf@ dynamic.uoregon. edu).

This research was supported by the Northwest Health Foundation Grant Number 2001-255 Child Abuse and Health: An Intervention (Freyd, PI). The manuscript preparation was also supported in part by the Trauma and Oppression Research Fund at the University of Oregon Foundation. The authors are grateful to the numerous contributions to this research made by Anne DePrince, Ann Yee, and from the members of the Freyd Dynamics Lab at the University of Oregon. The authors are also indebted to the reviewers and editors of this journal for helpful suggestions.

This paper was submitted, reviewed, and accepted under the editorship of James Chu, MD, and Jon Elhai, PhD.

Journal of Trauma \& Dissociation, Vol. 6(3) 2005

Available online at http://www.haworthpress.com/web/JTD

(C) 2005 by The Haworth Press, Inc. All rights reserved.

doi:10.1300/J229v06n03_04 
sive trauma survey or a long personality inventory, producing four groups of participants. All 99 participants were assessed at their initial visit for trauma history using the Brief Betrayal Trauma Survey (BBTS) and physical and mental symptoms. The BBTS assesses exposure to both traumas high in betrayal (such as abuse by a close other) and traumas low in betrayal but high in life-threat (such as an automobile accident). Exposure to traumas with high betrayal was significantly correlated with number of physical illness, anxiety, dissociation, and depression symptoms. Amount of exposure to other types of traumas (low betrayal traumas) did not predict symptoms over and above exposure to betrayal trauma. While neither the survey manipulation nor the writing intervention led to main effects on change in symptoms over time, there were interactions between betrayal trauma history and condition such that participants with many betrayal traumas fared better in the control conditions while participants with fewer betrayal traumas had better outcomes if they were placed in the trauma writing and/or survey conditions. We discuss ongoing and future research aimed at evaluating the role of increased structure in writing assignments as beneficial for those with severe histories of betrayal trauma. [Article copies available for a fee from The Haworth Document Delivery Service: 1-800-HAWORTH. E-mail address: <docdelivery@ haworthpress.com> Website: <http://www.HaworthPress.com> (c) 2005 by The Haworth Press, Inc. All rights reserved.]

KEYWORDS. Betrayal trauma, mental health, physical health, disclosure, writing

The phrase "betrayal trauma" refers to those traumas in which individuals or institutions that people depend on for survival harm or violate them in some way (Freyd, 1996, 2001). Betrayal traumas involve the depended-upon person or institution breaking an explicit or implied social agreement, such that a violation of trust occurs. Due to the dependent nature of the relationship between perpetrator and victim, the victim of the violation is unable to confront or sever ties with the perpetrator, being forced to ignore or accept the violation in order to preserve an apparently necessary relationship (Freyd, 1996, 2001). The victim thus is likely to remain in a position where future violations may occur.

Betrayal traumas may not threaten death or physical injury, but can be damaging to well-being, relationships, self-concept, and beliefs about others and the world. Such traumas represent a mismatch between what "should be" (e.g., people do not intentionally harm one another) and what is (you have been harmed by another person; DePrince \& 
Freyd, 2002). Freyd and colleagues have suggested that the most complete definition of trauma includes events evoking intense fear, social betrayal, or a combination of both (Freyd, 1999, 2001; Freyd, DePrince, \& Zurbriggen, 2001). Both fear and betrayal can be described either as continuous or categorical dimensions of trauma. A trauma can be said to either involve betrayal or not, but can also involve varying degrees of betrayal (e.g., abuse by a babysitter may be less betraying than abuse by a parent). The degree to which an event is traumatic may relate to the degree of fear and/or betrayal involved. Because betrayal is qualitatively different from fear, traumas that include elements of betrayal may lead to different outcomes than traumas that are only fear-based.

\section{THE CONSEQUENCES OF TRAUMA}

There have been many studies assessing the long-term consequences of experiencing trauma. The bulk of these studies have linked abuse in childhood or adulthood with adult physical and mental health symptoms and disorders (Felitti, 1991, 2002; Kendall-Tackett, 2000). Such studies have shown a strong relationship between abuse traumas and a number of health problems. Although these researchers have not specifically sought to study the consequences of betrayal trauma, most abuse traumas can be classified as betrayal traumas. A national survey of child abuse prevalence and characteristics revealed that a great majority $(85.5 \%)$ of child abuse is perpetrated by caregivers (parents: $81 \%$, legal guardians: $0.2 \%$, foster parents: $0.5 \%$, unmarried partners of parents: $2.9 \%$, residential facility staff: $0.2 \%$, and daycare providers: $0.7 \%$; Administration for Children and Families, 2002). Therefore, although it is likely that not all the trauma reported in the following studies is betrayal trauma, it is reasonable to assume that the bulk of it is.

In a study of 110 women drawn from a primary practice sample, childhood abuse and domestic abuse were positively correlated with pain symptoms (Kendall-Tackett, Marshall, \& Ness, in press) and diabetes symptoms (Kendall-Tackett \& Marshall, 1999). Runtz (2002) found that university women with a history of childhood physical abuse were more likely to experience a variety of health symptoms, and Romans and colleagues (2002) found that women with childhood and/ or adult abuse histories were more likely to experience chronic fatigue, bladder problems, pelvic pain, headache, chronic pain, asthma, diabetes, and heart problems. In two studies of men and women from primary practice samples, researchers found that those who had been victims of 
abuse had had more surgeries and engaged in more behaviors that were harmful to health (Kendall-Tackett, Marshall, \& Ness, 2000), were more likely to be obese, to have chronic headaches, asthma, and gastrointestinal symptoms, and were more likely to have high numbers of doctor office visits each year (Felitti, 1991). And in perhaps the most compelling piece of research linking trauma and health, a study of nearly 10,000 members of a health maintenance organization (HMO) found positive correlations between adverse childhood experiences and many of the leading causes of death in adults, including heart disease, cancer, and even skeletal fractures (Felitti et al., 1998).

History of childhood abuse has also been associated with later psychological symptoms and disorders such as depression, suicide attempt, conduct disorder, substance dependence, social anxiety (Nelson et al., 2002), generalized anxiety disorder, panic disorder (Kendler et al., 2000), and personality disorders (Johnson et al., 1999). The effects of childhood abuse are far-reaching, and clearly detrimental to those who have experienced such abuse.

The abovementioned studies provide support for the idea that betrayal trauma has many long-term negative effects. However, only a few studies have compared the effects of betrayal trauma with the effects of other types of trauma. Freyd, DePrince, and Zurbriggen (2001) found that abuse perpetrated by a caregiver (a high betrayal trauma) leads to less persistent memories than abuse perpetrated by a non-caregiver (a trauma with less betrayal). Atlas and Ingram (1998) reported that betrayal trauma is associated with posttraumatic stress to a greater extent than non-betrayal traumas in their sample of adolescent inpatients. And in a meta-analysis of studies of disaster victims, Norris and colleagues (2002) found that human-perpetrated disasters (i.e., mass violence) had a higher potential for causing severe psychological impairment in victims than natural or technological disasters. Although Norris and colleagues did not study betrayal specifically, they did compare human-perpetrated traumas (which we argue involve some type of betrayal) with other types of traumas, and their results are consistent with betrayal trauma theory (Freyd, 1996, 2001). More research is needed to determine whether betrayal trauma, over other types of trauma, can be implicated in a wide range of symptoms. Additionally, if the effects of betrayal trauma differ significantly from the effects of other traumas, it will be important to assess the effectiveness of current interventions with people who have experienced betrayal. One such intervention that is currently growing in popularity is the written disclosure paradigm. 


\section{WRITING FOR HEALTH}

A growing body of research suggests that writing about emotional experiences may provide benefits to physical health and general wellbeing (Pennebaker, 1997). In a seminal study on this topic, Pennebaker, Kiecolt-Glaser, and Glaser (1988) found that healthy undergraduate students who wrote about traumatic experiences in a controlled study showed a drop in visits to the student health center and an increase in cellular immune response following writing, compared with students who wrote about a trivial topic (e.g., describing their activities during the day, a social event they recently attended, or the shoes they were wearing). Another such study found that written emotional disclosure increased lymphocyte levels, marking improved immune function (Petrie, Booth, \& Pennebaker, 1998), and yet another found that such disclosure resulted in better immune response to a hepatitis B vaccination compared with a control group (Petrie et al., 1995). Writing about trauma appears to bolster the immune system and benefit health.

Physical health is not the only aspect of well-being to potentially benefit from writing. A study of individuals who had recently lost their jobs found that participants who wrote about the emotions associated with job loss were more likely to find new jobs within the months following writing than either control participants who wrote about their plans for finding another job or those who did not write (Spera, Buhrfeind, \& Pennebaker, 1994). Writing about stressful events has also been shown to improve academic performance of college students compared to control conditions (Lumley \& Provenzano, 2003; Pennebaker \& Francis 1996).

Most studies on the health benefits of writing have focused on health improvements in already healthy research participants. However, writing about stressful events has also led to disease-specific symptom improvements in research participants with mild to moderately severe asthma or rheumatoid arthritis (Smyth, Stone, Herewitz, \& Kaell, 1999). Writing appears to be beneficial across settings and symptoms, and has the potential to be a major public-health intervention for reducing symptoms and healthcare use. It is not yet clear, however, whether essay-writing is the only effective form of written disclosure.

Over the years of studying the impact of trauma on psychological development we have employed numerous survey methodologies to assess trauma history. One of our instruments, the Betrayal Trauma Inventory (BTI; Freyd, DePrince, \& Zurbriggen, 2001) is particularly lengthy and detailed. Occasionally in past research our participants 
have reported to us that completing the BTI has been meaningful because of the opportunity to disclose a history that has previously been kept secret. We have wondered whether the BTI is for some participants an intervention, similar in some ways to writing about trauma. Using the BTI and a neutral control measure, we assess this possibility in the current study.

\section{REVISITING BETRAYAL}

Past studies investigating the relationships among trauma, health, and writing have not looked at betrayal as a factor, yet as discussed earlier, betrayal appears to differ in some ways from other types of trauma. There appear to be relationships between betrayal trauma and health, and between health and writing, but so far there has not been a writing study that specifically asked participants to write about betrayal.

One challenge to studying trauma populations is that by recruiting people who have experienced significant trauma, the participants are primed to think about trauma before even entering the study through the recruitment procedures. The standard writing paradigm randomly assigns participants to either an emotional writing condition or a neutral writing condition. Priming participants in the control condition to think about trauma prior to beginning the study may change the outcome in some way. One way around this would be to recruit participants based on a correlate of trauma, for example health problems. As mentioned above, many chronic pain disorders and chronic health problems are related to trauma. It seems likely then, that it would be possible to recruit a participant pool densely populated by individuals with trauma histories by asking people with chronic pain and health problems to participate in a study, and this is the methodology we used in the current study.

In summary, in the current study we hypothesized that baseline symptoms would be related to trauma history, and that symptoms would be more highly correlated with betrayal trauma than with other types of trauma. We hypothesized that writing about betrayal, as well as survey disclosure of betrayal traumas, would be beneficial within a traumatized population. We expected to find that participants in trauma disclosure conditions would show reductions in symptoms six months after disclosure, while control participants would not. However, we also questioned whether the number and types of traumas that participants have experienced may be related to their experiences with writing and survey 
completion. This final question is exploratory in nature, and no specific hypotheses were posited.

\section{METHOD}

The procedures used in this study were approved by the University of Oregon Institutional Review Board.

\section{Participants}

Participants for this study were recruited from a small- to mediumsized city and surrounding area using fliers posted on bulletin boards in various community locations, including homeless shelters, laundromats, and bus stops. The fliers stated that adults dealing with chronic pain and/or chronic health problems were needed for a psychological research study. Interested parties responding to the flier were screened in a brief phone interview. Those who reported being over 18 years of age, experiencing chronic pain or a chronic health problem lasting for the past 12 months or longer, and the ability to read and write comfortably in English were asked to participate in the study. Participants in the study each took part in one to four sessions in the lab, and received between $\$ 20$ and $\$ 75$ for their participation, the amount depending on the number of sessions completed. Participants were paid after each session.

Of 102 participants who entered into the study, 80 completed all four sessions. Three participants did not complete the first session (due to hostility towards the researchers or inability to complete the study in a timely manner) and will be excluded from any further discussion. Eighteen participants successfully completed the first session but failed to return for one or more of the second, third, and fourth sessions, mostly due to moving out of the area or unreliable contact information. Participants who did not return were evenly distributed among experimental conditions, and were no different from participants who finished the study in age, income, educational attainment, or ethnicity. However, significantly more male participants did not return $(n=12)$ than female participants $(n=7), \chi^{2}(1, N=99)=4.14, p=.04$.

Ninety-nine participants, 57 women and 42 men of varying ages and backgrounds, provided usable data during the first session. Participants' ages ranged from 18 to 70 years $(M=42.1, S D=11.9)$, educational attainment ranged from eighth grade through $\mathrm{PhD}(M=14.0$, approxi- 
mately two years of college, $S D=2.9$ ), and yearly income ranged from $\$ 0$ to $\$ 50,000(M=13,427, S D=12,321)$. For a racial/ethnic identification question, participants were allowed to check as many groups as applied to them. The majority of the sample identified as White/Caucasian $(n=86)$, followed by Native American $(n=12)$, Hispanic $(n=5)$, Black/African American $(n=1)$, and other $(n=8)$. Two participants gave no response. A variety of health conditions were reported by participants, and many had more than one significant health problem. A large majority of participants reported having one or more of the following conditions: fibromyalgia, chronic fatigue, chronic pain (either related to a previous injury, medical syndrome, or unidentified cause), asthma, severe allergies. All conditions listed by participants were chronic in nature, some with known causes and others with unknown causes.

\section{Materials}

Demographic questions. Detailed demographic and other personal information was collected, including current and past social and financial status, physical and mental illness, therapy experience, drug use (prescription and non-prescription), and single question ratings of perceived health, stress level, sleep, and mood. Additionally, participants were asked about several life stressors previously or currently experienced, including having been placed in foster care, spending time in jail, and financial difficulties.

Participants were also administered a number of instruments assessing trauma history and physical and mental health symptoms. The symptom measures were time-bound such that participants were instructed to report how frequently they had experienced each symptom during the past month. In contrast, the original measures asked participants to report on symptom frequency experienced over longer periods of time. This was done for comparison purposes between scores obtained prior to the intervention and those obtained following the intervention, approximately six months later.

Pennebaker Inventory of Limbic Languidness, time bound (PILL-t; Pennebaker, 1982). The PILL-t assesses the degree to which participants have experienced each of 54 physical health symptoms (e.g., headaches, chest pains, abdominal pain) during the last month, on a 5 -point Likert scale ranging from 0 ("never") to 4 ("almost every day"). The PILL-t also asks participants how many days they have been sick, how many days activity has been restricted due to illness, and how 
many visits to a doctor they have made in the last month. The recommended way to score the symptom part of the PILL-t is to sum the total number of items on which individuals score 3 or higher (indicating about once a week or more frequent), resulting in a score ranging from 0 to 54. Using this scoring method, a mean score of $17.9(S D=4.5)$ was obtained on a sample of 939 college students in the original study assessing the PILL's psychometric value, which was found to be high in terms of reliability and validity (Pennebaker, 1982).

Trauma Symptom Checklist 40, time bound (TSC40-t; Briere \& Runtz, 1989). The TSC-40-t is a 40-item checklist, assessing symptoms commonly associated with the experience of traumatic events. Respondents are asked to indicate how frequently they experienced each symptom on a scale of 0 ("never") to 3 ("very often"). The TSC-40 is composed of six symptom subscales: anxiety, depression, dissociation, sexual abuse trauma index, sexual problems, and sleep disturbances. Sample items include "anxiety attacks" and "trouble getting along with others." The TSC-40-t is scored by summing responses, for a resulting score falling between 0 and 120, with higher scores indicating greater trauma symptomatology. The average TSC-40 score in a study of 438 female students was 66.8, and for those who had experienced child and/ or adult abuse, the mean ranged from 70.4 to 77.4 (Gold, Milan, Mayall, \& Johnson, 1994). The measure has been shown to have good reliability and validity (Briere \& Runtz, 1989; Elliott \& Briere, 1992).

Dissociative Experiences Scale, time bound (DES-t; Carlson \& Putnam, 1993). This 28-item questionnaire assesses the frequency with which participants have had particular dissociative experiences during the past month. Respondents select a percentage ranging from 0 to 100 , increasing in $10 \%$ intervals, to indicate how frequently each item is experienced. Items range from normal dissociative experiences such as "spacing out" during a conversation with someone to more unusual experiences such as not recognizing oneself in the mirror. The overall DES score is obtained by averaging the 28 item scores, yielding a score ranging from 0 to 100 . Scores above 20 suggest the presence of highly dissociative experiences and that further clinical assessment is warranted, whereas scores below 10 fall within the normal range of dissociative experiences (Carlson \& Rosser-Hogan, 1993). The DES has been to shown to have very good validity and reliability, and good overall psychometric properties in a number of studies (see Briere, 1997 for a review). A relationship between the development of dissociative symptoms and traumatic experiences has been documented (e.g., Bernstein \& Putnam, 1986; Chu \& Dill, 1990). 
Brief Betrayal Trauma Survey (BBTS; Goldberg \& Freyd, 2003a). The BBTS asks participants about the number of times they have experienced 12 types of traumatic events both before and after age 18, using a six-point scale ranging from "never" to "more than 100 times." Events on the survey range in level of betrayal from natural disasters (no betrayal) to sexual abuse by someone close (very high betrayal). The questions avoid using labels for the events and instead describe them. For example one question asks how many times a participant was "made to have sexual contact by someone with whom (they) were not close" as opposed to asking how many times they experienced sexual abuse by a stranger.

The questions on the BBTS can be divided into items that describe trauma in which a relatively high level of betrayal is involved (the "high betrayal" traumas; HB) and items in which a relatively low level of betrayal is involved (the "low betrayal" traumas; LB). An item capturing an experience lower on the betrayal dimension is one which does not involve another person as the perpetrator, such as "you have been in a major earthquake, fire, flood, hurricane, or tornado that resulted in significant loss of personal property, serious injury to yourself or a significant other, the death of a significant other, or the fear of your own death." For events involving perpetrators, respondents are asked to report on those perpetrated by individuals with whom they were close separately from those perpetrated by individuals with whom they were not close, to distinguishing between experiences lower and higher on the betrayal dimension of trauma. For example, an event perpetrated by someone with whom the respondent is close is considered higher in betrayal, such as "you were made to have some form of sexual contact, such as touching or penetration, by someone with whom you were very close (such as a parent or lover)." On the other hand, the same experience perpetrated by someone with whom the respondent was not close is considered lower in betrayal. The HB subscale score is calculated by summing the number of $\mathrm{HB}$ items that a respondent has experienced at least one time, and the LB subscale score is calculated by summing the number of LB items experienced at least once. See Goldberg and Freyd (2003b) for more information about this measure.

Betrayal Trauma Inventory (BTI; Freyd, DePrince, \& Zurbriggen, 2001). The BTI is used to gather detailed information about childhood (prior to age 16) physical and emotional punishment, and sexual experiences. For each of the 44 events included in the measure, respondents are asked to first indicate whether they experienced the event and if so, to provide further information about it. Like the BBTS, the BTI de- 
scribes events as opposed to labeling them, and does not make inherent judgments about whether each experience was abusive. For example, one physical punishment item asks if "someone punched you with a closed fist, or kicked you, anywhere on your body." A sample emotional punishment item asks whether "someone threatened to kill you or physically or sexually violate you." Similarly, one question eliciting information about childhood sexual experiences asks if "someone had you fondle them (for example, touch or caress their genitals or other parts of their body) in a sexual way." This instrument was not scored for the purpose of the current study; rather, it was tested as an intervention.

International Personality Item Pool Survey (IPIP; Goldberg, 1999). A lengthy personality survey was used as a control condition administered to half of the participants in the first session of the study (the other half completed the BTI). Participants completing this survey are asked to rate how accurately each of the 461 statements, such as "express myself easily," "seldom joke around," and "plan my life logically" were self-descriptive, using a five-point Likert scale ranging from "very inaccurate" to "very accurate." Like the BTI described above, this instrument was not scored for this study because its purpose was to serve as control for the intervention.

Writing instructions. Two sets of writing instructions were used. Participants in the experimental group were asked to write about the most disturbing or distressing event or series of events they have experienced, which involved at least one other person. Participants were further instructed to write about their deepest emotions surrounding the event(s). Participants in the control group were asked to write about what they have done to maintain their health in the past, and how they planned to maintain and improve their health in the future, outlining specific strategies, with further instructions to be as objective as possible, avoiding writing about their feelings. For participants in both groups, writing instructions requested increasing detail at each of the four sessions. The general template for the writing instructions was taken from research by Pennebaker (1994).

\section{Procedure}

Eligible participants were scheduled by phone for a first session in the laboratory. Second and third sessions were scheduled for one and two weeks, respectively, after completion of the first session, and participants were contacted by phone six months after the first session to schedule the fourth and final session of the study. 
The four experimental conditions. There were four conditions in this $2 \times 2$, writing by survey, experimental design. The writing condition depended on the type of writing instruction given at each writing session (traumatic or health), and the survey condition was determined by the type of survey administered during the first session (BTI or IPIP). These surveys were completed immediately prior to the first writing assignment during the pretest session. Thus, there were four conditions in this study: BTI plus trauma writing (BTI-T), BTI plus health writing (BTI-H), IPIP plus trauma writing (IPIP-T), and IPIP plus health writing (IPIP-H). These four conditions were created to determine whether trauma writing or completion of the BTI might individually have an effect on outcome measures, or if the combination of filling out the BTI and writing about trauma might have a differentially large effect.

Participants were randomly assigned to one of the four conditions upon entry into the study. Experimenters were blind to participant condition, and participant identities could not be linked to completed questionnaires or writing samples.

The four sessions. Participants were tested individually. To maintain confidentiality while tracking participants over time, a double-coding system was used. A number code was attached to each participant's name and contact information and a second code was attached to his or her testing materials. The list linking the two codes was destroyed prior to data analysis.

During the first session, participants were instructed that they could skip any questions they were uncomfortable with, or stop participation at any time without penalty. Written informed consent was obtained at this time. Following general instructions, the experimenters left the room and participants filled out the dependent measure questionnaire packet, followed by the long survey (BTI or IPIP). Participants were then given general instructions for completing the writing assignment, and were timed while they wrote about the assigned topic for 20 minutes. At the end of the session participants were given a general debriefing and told that they would be provided with more information about the study, including the hypotheses, after they completed the final session. Participants were paid \$20 for participating in the first session.

Each of the second and third sessions was shorter than the first, and included only a brief demographic/personal information update and a writing assignment. Participants were paid $\$ 10$ after each of the second and third sessions.

The fourth session was very similar to the first session. Participants filled out the dependent measure questionnaire packet with the abridged 
version of the demographic section. Following completion of all dependent measures, all participants completed the BTI regardless of which survey condition they had been in during the first session. Participants then completed a 20-minute writing assignment (this was not part of the intervention, will be part of a future study of essay content). Following this final session participants were completely debriefed on the purpose of the study, including the hypotheses. Participants were paid $\$ 35$ at the end of this final session.

\section{Data Analysis}

Exploratory analysis of baseline symptom data revealed one participant who did not meet criteria for inclusion. This participant reported no significant physical symptoms and since participants were recruited based on their experience with chronic pain and/or health problems, this participant was removed from the analysis to eliminate health status as a possible confound. The remaining participants reported that they had significant physical symptoms which they experienced at least weekly.

Prior to analyzing the data, difference scores were calculated for each symptom measure. Each difference score was calculated by subtracting the pretest score (collected at the first administration of the measures) and posttest score (taken from the second administration at the sixmonth follow-up) from one another, such that a positive score means the participant's symptoms improved, a score of zero means that there was no change, and a negative score means the symptoms worsened.

Descriptive statistics were calculated for each measure used in the analyses, and are summarized in Table 1. To determine whether demographic characteristics should be controlled for in our analyses, age, gender, education, and income level were correlated with our dependent measures. No significant relationships were found. Due to small $n \mathrm{~s}$ in all ethnic/racial groups other than White/Caucasian, ethnic/racial identity was not included in any analysis.

To test the hypothesis that baseline symptoms would be related to betrayal trauma more strongly than to other types of trauma, the HB and LB subscales of the BBTS were used as predictor variables in simultaneous entry linear regressions with the symptom difference scores (PILL, the TSC-40, and the DES). It was initially determined that there was a strong relationship between participants' HB scores and LB scores, $r(95)=.60, p<.001$. In order to assess the unique contributions of $\mathrm{HB}$ and $\mathrm{LB}$ in predicting symptoms, HB and LB were entered as simultaneous predictors, and the squared semi-partial correlations be- 
TABLE 1. Descriptive Statistics for PILL, TSC, DES, and BBTS

\begin{tabular}{lcccccc}
\hline & \multicolumn{2}{c}{ Time 1 } & \multicolumn{2}{c}{ Time 2 } & \multicolumn{2}{c}{ Difference Score } \\
\hline Measure & $\mathrm{M}$ & $\mathrm{SD}$ & $\mathrm{M}$ & $\mathrm{SD}$ & $\mathrm{M}$ & $\mathrm{SD}$ \\
\hline PILL & 22.15 & 10.94 & 21.62 & 10.70 & -0.15 & 6.45 \\
\hline TSC & 79.26 & 20.31 & 77.71 & 18.54 & -0.74 & 14.42 \\
\hline DES & 10.28 & 9.89 & 10.10 & 9.52 & -0.03 & 9.17 \\
\hline BBTS & & & & & & \\
$\quad$ LB subscale & 2.71 & 2.01 & & & & \\
HB subscale & 4.23 & 2.87 & & & & \\
\hline
\end{tabular}

Note. Time 1 scores include all participants completing the first session $(n=98)$, Time 2 scores and difference scores only include those who completed all sessions of the study $(n=79)$. BBTS $=$ Brief Betrayal

Trauma Scale; DES = Dissociative Experiences Scale; HB = High Betrayal; LB = Low Betrayal; PILL = Pennebaker Inventory of Limbic Languidness; TSC = Trauma Symptom Checklist-40.

tween each predictor and each dependent measure are reported. See Table 2 for a summary of these analyses. Similar regression analyses were conducted using each of the six subscales of the TSC as dependent measures, and the outcome is summarized in the results section below.

To test the hypotheses that writing condition and survey condition would predict improvements in symptoms, and that betrayal trauma history might interact with condition, a series of 2 X 2 main effect and interaction model analyses of variance (ANOVAs) were conducted. Prior to conducting these ANOVAs, we created a categorical variable from the continuous HB variable. The use of a categorical variable was necessary in order to facilitate interpretation of the results of the interaction tests. The categorical HB variable (HBcat) was created by classifying the top $33 \%$ of HB scores as "many HB traumas" the middle $33 \%$ as "moderate HB traumas" and the lowest $33 \%$ as "few HB traumas." Interactions between HBcat and survey condition and between HBcat and writing condition were calculated for effects on difference scores for the PILL, the DES, and the TSC. The results are summarized in Table 3.

\section{RESULTS}

On average, participants had experienced approximately four different kinds of high betrayal traumas and approximately two to three other types of traumas. Participants in our sample had relatively high average PILL scores (compared with norms obtained by Pennebaker, 1982) as 
TABLE 2. Relationships Between HB, LB, and Baseline Symptom Measures $(N=$ 95, $d f=2,92)$

\begin{tabular}{|c|c|c|c|c|c|}
\hline $\begin{array}{l}\text { Dependent } \\
\text { Measure } \\
\end{array}$ & Adjusted $R^{2}$ & $F$ & Predictors & Zero-order $r$ & $\begin{array}{c}\text { Squared } \\
\text { Semi-partial }\end{array}$ \\
\hline \multirow[t]{2}{*}{ PILL } & .17 & $10.85^{\star * *}$ & LB & $.34^{\star * *}$ & .01 \\
\hline & & & $\mathrm{HB}$ & $.42^{* \star *}$ & $.08^{\star \star}$ \\
\hline \multirow[t]{2}{*}{ TSC } & .22 & $14.34^{\star * *}$ & LB & $.38^{\star \star *}$ & .02 \\
\hline & & & $\mathrm{HB}$ & $.48^{\star \star \star}$ & $.12^{\star \star *}$ \\
\hline \multirow[t]{2}{*}{ DES } & .04 & $3.04^{*}$ & LB & .06 & .01 \\
\hline & & & $\mathrm{HB}$ & $.23^{*}$ & $.06^{*}$ \\
\hline
\end{tabular}

${ }^{*} p=.05,{ }^{* *} p<.01,{ }^{* * *} p<.001$

Note. DES = Dissociative Experiences Scale; HB = High Betrayal; LB = Low Betrayal; PILL = Pennebaker Inventory of Limbic Languidness; TSC = Trauma Symptom Checklist- 40 .

TABLE 3. Main Effects for Writing Condition and Survey Condition, and Interactions for HBcat and Writing Condition, and HBcat and Survey Condition, on Difference Scores for the PILL, DES, and TSC (see Figure 1) $(\mathrm{N}=77, \mathrm{df}=2,71)$

\begin{tabular}{cccc}
\hline & $\begin{array}{c}\text { Dependent } \\
\text { Measure }\end{array}$ & $\begin{array}{c}\text { Condition } \\
\text { Main Effect }\end{array}$ & $\begin{array}{c}\text { Condition and Hbcat } \\
\text { Interaction }\end{array}$ \\
\cline { 2 - 4 } Writing & PILL & $F$ & $F$ \\
\hline TSC & 0.47 & 1.07 \\
\hline Survey & DES & 0.36 & 0.80 \\
\hline & PILL & 1.32 & $6.46^{\text {* }}$ \\
\hline & TSC & 0.96 & $6.93^{\text {* }}$ \\
\hline & DES & 0.05 & 0.07 \\
\hline
\end{tabular}

${ }^{\star *} p<.01$

Note. HBcat $=$ High Betrayal (categorically coded); DES = Dissociative Experiences Scale; PILL = Pennebaker Inventory of Limbic Languidness; TSC = Trauma Symptom Checklist-40.

would be expected in a sample of ill adults. However, there was quite a bit of variation in physical symptoms, as evidenced by a relatively large standard deviation for PILL scores. Dissociation scores for participants in this sample were moderate, and average TSC scores were on the higher end of average scores for a traumatized population (Gold, Milan, Mayall, \& Johnson, 1994). These results are summarized in Table 1.

Significant relationships were found between baseline symptoms and betrayal trauma, such that more betrayal trauma exposure was re- 
lated to higher symptom scores on the PILL, TSC, and DES (see Table 2 ). Amount of exposure to other types of traumas (low betrayal traumas) did not predict symptoms over and above exposure to betrayal trauma. Similarly, for each of the six subscales of the TSC correlations with HB controlling for LB were significant (but were not for LB controlling for $\mathrm{HB}$ ), with the strongest correlations emerging for $\mathrm{HB}$ with anxiety (zero-order $r=.49$; semi-partial $r=.36 ; p<.001$ ), HB with dissociation (zero-order $r=.43$; semi-partial $r=.33 ; p<.001$ ), and $\mathrm{HB}$ with depression (zero-order $r=.42$; semi-partial $r=.31 ; p<.01$ ).

There were no significant group differences between the trauma writing condition and the control writing condition or between the BTI survey condition and the control (IPIP) survey condition (see Table 3). A significant HBcat by survey condition interaction was found for PILL difference scores and a significant HBcat by writing condition interaction was found for DES difference scores (see Figure 1). The direction of the effects were such that people categorized as having few HB traumas showed better outcomes in both the trauma writing and survey conditions and people categorized as having many HB traumas showed better outcomes in the control conditions.

\section{DISCUSSION}

Strong associations between betrayal trauma exposure and negative physical and psychological status were found in this sample of ill adults. This pattern of results has been replicated with data recently collected in our laboratory using a healthy student population (Goldsmith, Freyd, \& DePrince, 2004). Individuals who have experienced betrayal trauma, then, are an important target group for whom to develop effective therapeutic interventions. In addition, findings from the current study suggest a need to develop interventions that address the differential impact of different types of trauma. There appear to be interactions between disclosure intervention and number of betrayal traumas experienced such that people who have experienced many betrayal traumas have negative reactions to disclosing abuse either via writing or completing a trauma survey and those who have experienced few betrayal traumas seem to benefit from disclosure.

The writing intervention is a potentially powerful public health intervention. It is exciting to imagine the potential benefit of writing about emotional and traumatic experiences on a regular basis, as part of the school curriculum for instance. However, it is possible that writing in- 
FIGURE 1. Interactions Between HBcat (High Betrayal Categorical Variable) and Survey Condition for PILL Difference Scores, and Between HBcat and Writing Condition for DES Difference Scores (See Table 3).
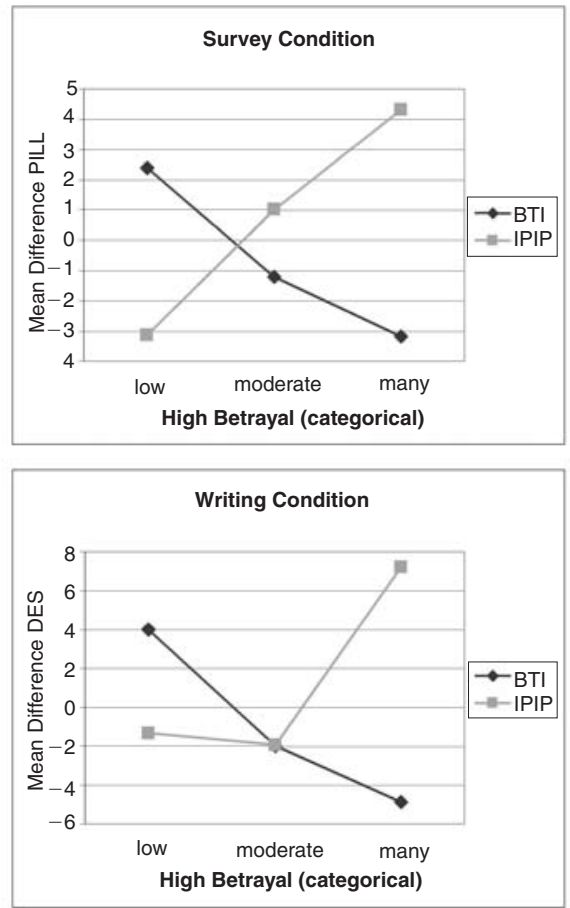

terventions do not adequately address the needs of people who have experienced more severe interpersonal traumas. Batten and her colleagues (2002) reported that writing about a recent rape was not helpful in their sample. In the current study, the writing intervention did not appear to have beneficial effects for this sample of participants with chronic pain and/or health difficulties. Further, although disclosure of betrayal traumas via trauma survey completion was expected to have beneficial effects, as was suggested by anecdotal reports by participants in previous research by the authors, no effect of survey condition emerged. It could be that written disclosure, as used in these studies, is not a sufficient intervention in cases where the participants are experiencing significant physical and mental health impairments. Because higher levels of betrayal trauma are associated with greater impairment, it may be that the writing intervention is not suited to betrayal traumas. 
However, it could simply be that the standard paradigm requires modifications when applied to betrayal trauma. Although on average participants' symptoms did not improve or worsen six months after writing there was substantial variability in participants' outcomes, as evidenced by relatively large standard deviations in change scores (see Table 1). Thus it appears that some participants' symptoms improved and some stayed the same, while others actually worsened. The current study has not uncovered correlates of improvement, but future research could be directed at doing just that. If such correlates are found, modifications to the standard writing paradigm may be required in the form of adding complementary components. For instance, because of the interpersonal nature of betrayal traumas, some have argued that interventions that include an interpersonal component may prove more beneficial than traditional trauma treatments (Birrell \& Freyd, in press; Feske, 2001; Krupnick, 2000). In addition, research suggests that helpful social response to disclosure is very important to the well-being of assault victims (Ullman, 2003), and while the writing paradigm does not itself inflict negative social response, neither does it provide much in the way of positive response. Further research is necessary to determine whether changing the standard writing paradigm to include elements found to be therapeutic in other contexts would make it an effective intervention for betrayal trauma survivors.

Modifications to the standard writing paradigm in the form of directing the writing process may also increase its effectiveness as a betrayal trauma intervention. There is evidence suggesting that the benefit of writing may be related to organizing thoughts and feelings around the event being written about, including making causative interpretations, and being able to sequentially order the events of the traumatic experience (Pennebaker, 1993, 1997; Pennebaker \& Graybeal, 2001). For example, in a study of 64 undergraduate students writing about traumas, those who experienced the greatest health improvements tended to use a higher proportion of negative emotion words than positive emotion words, and increasing use of insight, causal, and associated cognitive words over three or four days of writing (Pennebaker, 1993). That is, the construction of a coherent story, which includes the expression of negative emotions, appeared to be most beneficial in therapeutic writing. While expressly directing the structure of writing in this way may prove beneficial for all forms of emotional experiences, it may be particularly important in populations of individuals experiencing more complex betrayal traumas. Because people experiencing betrayal trauma appear to suffer more emotional distress, increased direction may be necessary to 
improve the structure of the writing to levels that are thought to be beneficial. Modifying the standard writing paradigm in this way needs to be experimentally manipulated to test its effectiveness in populations of individuals who have experienced betrayal trauma.

The current study contributes to the trauma literature by providing support for the differential impact of traumas that vary in level of betrayal, and by providing evidence that one size may not fit all in interventions aimed at trauma sequelae. In future research we will evaluate attempts to modify disclosure instructions and complement disclosure with other therapeutic components in cases of high betrayal trauma. The current study had several limitations in terms of the participant population and the design. First, the sample was comprised of highly physically symptomatic adults, nearly all of whom had experienced some betrayal trauma, and multiple significant traumas. While studying a population having experienced a great deal of betrayal trauma allowed us to investigate the effectiveness of the writing intervention in this population, the fact that they were also highly symptomatic means that the generalizability of our results to other populations is limited. In addition, that the sample consisted of a rather homogenous group of adults in terms of ethnicity also limits generalizability. On the other hand, participants in this study were relatively heterogeneous in terms of their health status. It is possible that some of the outcome variability was due to variable health status and clearer effects could be found in a sample of participants with one particular type of health problem. It could also be that recruiting based on health status biased our results, and screening participants for inclusion based on trauma history would be more effective. In terms of study design, it may be that for individuals experiencing high levels of or chronic betrayal trauma, the processing of these experiences via written disclosure may take longer than six months. Future research should add later follow-up assessments to determine whether this is the case. Additionally, the impact of completing the dependent measure surveys (which included some trauma disclosure for all participants, in the form of the BBTS) was not assessed. Future studies could employ a wait-list design to separate the effects of survey completion from the effects of written disclosure. Research is currently underway to address some of these limitations and to assess the role of structure and other content characteristics of traumatic writing on well being. 


\section{REFERENCES}

Administration for Children and Families. (2002). Child maltreatment 2002. Washington, DC: Department of Health \& Human Services. Retrieved August 5, 2004 from http://www.acf.hhs.gov/programs/cb/publications/cm02/cm02.pdf.

Atlas, J.A., \& Ingram, D.M. (1998). Betrayal trauma in adolescent inpatients. Psychological Reports, 83, 914.

Batten, S.V., Follette, V.M., Hall, M.L R., \& Palm, K.M. (2002). Physical and psychological effects of written disclosure among sexual abuse survivors. Behavior Therapy, 33, 107-122.

Bernstein, E.M., \& Putnam, F.W. (1986). Development, reliability, and validity of a dissociation scale. Journal of Nervous \& Mental Disease, 174, 727-735.

Birrell, P.J. \& Freyd, J.J. (in press). Betrayal Trauma: Relational models of harm and healing. Journal of Trauma Practice.

Briere, J., \& Runtz, M. (1989). The Trauma Symptom Checklist (TSC-33): Early data on a new scale. Journal of Interpersonal Violence, 4(2), 151-163.

Briere, J. (1997). Psychological assessment of adult posttraumatic states. Washington, DC: American Psychological Association.

Carlson, E.B., \& Putnam, F.W. (1993). An update on the Dissociative Experiences Scale. Dissociation, 6(1), 16-27.

Carlson, E.B., \& Rosser-Hogan, R. (1993). Mental health status of Cambodian refugees ten years after leaving their homes. American Journal of Orthopsychiatry, 63, 223-231.

Chu, J.A, \& Dill, D.L. (1990). Dissociative symptoms in relation to childhood physical and sexual abuse. American Journal of Psychiatry, 147, 887-892.

DePrince, A.P., \& Freyd, J.J. (2002). The harm of trauma: Pathological fear, shattered assumptions, or betrayal? In J. Kauggman (Ed.), Loss of the assumptive world: A theory of traumatic loss (pp. 71-82). New York: Taylor and Francis.

Elliott, D.M. \& Briere, J. (1992). Sexual abuse trauma among professional women: Validating the Trauma Symptom Checklist-40 (TSC-40). Child Abuse and Neglect, 16, 391-398.

Felitti, V.J. (1991). Long-term medical consequences of incest, rape, and molestation. Southern Medical Journal, 84, 328-331.

Felitti, V.J. (2002). The relationship between adverse childhood experiences and adult health: Turning gold into lead. The Permanente Journal, 6, 44-47.

Felitti, V.J., Anda, R.F., Nordenberg, D., Williamson, D.F., Spitz, A.M., Edwards, V., Koss, M.P., \& Marks, J.S. (1998). Relationship of childhood abuse and household dysfunction to many of the leading causes of death in adults. American Journal of Preventive Medicine, 14, 245-258.

Feske, U. (2001). Treating low-income and African American women with posttraumatic stress disorder: A case series. Behavior Therapy, 32, 585-601.

Freyd, J.J. (1996). Betrayal trauma: The logic of forgetting childhood abuse. Cambridge, MA: Harvard University Press.

Freyd, J.J. (1999). Blind to betrayal: New perspectives on memory for trauma. The Harvard Mental Health Letter, 15(12), 4-6. 
Freyd, J.J. (2001). Memory and dimensions of trauma: Terror may be 'all-too-well remembered' and betrayal buried. In J.R. Conte (Ed.), Critical issues in child sexual abuse: Historical, legal, and psychological perspectives (pp. 139-173). Thousand Oaks, CA: Sage Publications.

Freyd, J.J., DePrince, A.P., \& Zurbriggen, E.L. (2001). Self-reported memory for abuse depends upon victim-perpetrator relationship. Journal of Trauma \& Dissociation, 2(3), 5-17.

Gold, S.R., Milan, L.D, Mayall, A, \& Johnson, A.E. (1994). A cross-validation study of the Trauma Symptom Checklist: The role of mediating variables. Journal of Interpersonal Violence, 9, 12-26.

Goldberg, L.R. (1999). A broad-bandwidth, public domain, personality inventory measuring the lower-level facets of several five-factor models. In I. Mervielde \& I. Deary \& F.D. Fruyt \& F. Ostendorf (Eds.), Personality Psychology in Europe (vol. 7, pp. 7-28). Tilburg, The Netherlands: Tilburg University Press.

Goldberg, L.R. \& Freyd, J.J. (2003a). The Brief Betrayal Trauma Survey (BBTS). Retrieved April 1, 2003 from http://dynamic.uoregon.edu/ jjf/bbts/.

Goldberg, L.R. \& Freyd, J.J. (2003b). Self-reports of potentially disturbing experiences in an adult community sample: Gender differences in event frequencies, test-retest stabilities, and the hierarchical factor structure of the items in a brief betrayal-trauma survey. Manuscript submitted for publication.

Goldsmith, R.E., Freyd, J.J., \& DePrince, A.P. (2004). Health correlates of exposure to betrayal trauma. Poster presented at the Annual Meeting of the American Association for the Advancement of Science, Seattle, February 12-16, 2004.

Johnson, J.G., Cohen, P., Brown, J., Smailes, E.M., \& Bernstein, D.P. (1999). Childhood maltreatment increases risk for personality disorders during early adulthood. Archives of General Psychiatry, 56, 600-606.

Kendall-Tackett, K. (2000). The long-term health effects of victimization. Joining Forces, 5(1), 1-4.

Kendall-Tackett, K., \& Marshall, R. (1999). Victimization and diabetes: An exploratory study. Child Abuse \& Neglect, 23, 593-596.

Kendall-Tackett, K., Marshall, R., \& Ness, K. (2000). Victimization, healthcare use and health maintenance. Family Violence \& Sexual Assault Bulletin, 16, 18-21.

Kendall-Tackett, K., Marshall, R., \& Ness, K. (2003). Chronic pain syndromes and violence against women. Women and Therapy, 26(1-2), 45-56.

Kendler, K.S., Bulik, C.M., Silberg, J., Hettema, J.M., Myers, J., \& Prescott, C.A. (2000). Childhood sexual abuse and adult psychiatric and substance use disorders in women: An epidemiological and cotwin control analysis. Archives of General Psychiatry, 57, 953-959.

Krupnick, J.L. (2000). Interpersonal psychotherapy for PTSD following interpersonal trauma. Directions in Psychiatry, 20, 237-252.

Lumley, M.A., \& Provenzano, K.M. (2003). Stress management through written emotional disclosure improves academic performance among college students with physical symptoms. Journal of Educational Psychology, 95, 641-649.

Nelson, E.C., Heath, A.C., Madden, P.A.F., Cooper, M.L., Dinwiddie, S.H., Bucholz, K.K., Glowinski, A., McLaughlin, T., Dunne, M.P., Statham, D.J., \& Martin, N.G. 
(2002). Association between self-reported childhood sexual abuse and adverse psychosocial outcomes. Archives of General Psychiatry, 59, 139-145.

Norris, F.H., Friedman, M.J., Watson, P.J., Byrne, C.M., Diaz, E., \& Kaniasty, K. (2002). 60,000 disaster victims speak: Part I. An empirical review of the empirical literature, 1981-2001. Psychiatry, 65, 207-239.

Pennebaker, J.W. (1982). The Psychology of physical symptoms. New York: SpringerVerlag.

Pennebaker, J.W. (1993). Putting stress into words: Health, linguistic, and therapeutic implications. Behavior Research \& Therapy, 31, 539-548.

Pennebaker, J.W. (1994). Hints on running a writing experiment. Retrieved November 12 , 2003, from http://homepage.psy.utexas.edu/homepage/faculty/Pennebaker/Reprints/ Hints.DOC.

Pennebaker, J.W. (1997). Writing about emotional experiences as a therapeutic process. Psychological Science, 8(3), 162-166.

Pennebaker, J.W., \& Francis, M.E. (1996). Cognitive, emotional and language processes in disclosure. Cognition and Emotion, 10(6), 601-626.

Pennebaker, J.W., \& Graybeal, A. (2001). Patterns of natural language use: Disclosure, personality, and social integration. Current Directions in Psychological Science, 10(3), 90-93.

Pennebaker, J.W., Kiecolt-Glaser, J.K., \& Glaser, R. (1988). Disclosure of traumas and immune function: Health implications for psychotherapy. Journal of Consulting and Clinical Psychology, 56, 239-245.

Petrie, K.J., Booth, R.J., \& Pennebaker, J.W. (1998). The immunological effects of thought suppression. Journal of Personality and Social Psychology, 75, 1264-1272.

Petrie, K.J., Booth, R.J., Pennebaker, J.W., Davison, K.P., \& Thomas, M.G. (1995). Disclosure of trauma and immune response to a hepatitis B vaccination program. Journal of Consulting and Clinical Psychology, 63, 787-792.

Romans, S., Belaise, C., Martin, J., Morris, E., \& Raffi, A. (2002). Childhood abuse and later medical disorders in women. Psychotherapy and Psychosomatics, 71, 141-150.

Runtz, M.G. (2002). Health concerns of university women with a history of child physical and sexual maltreatment. Child Maltreatment, 7, 241-253.

Smyth, J.M., Stone, A.A., Hurewitz, A., \& Kaell, A. (1999). Effects of writing about stressful experiences on symptom reduction in patients with asthma or rheumatoid arthritis. JAMA, 281, 1304-1309.

Spera, S.P., Buhrfeind, E.D., \& Pennebaker, J.W. (1994). Expressive writing and coping with job loss. Academy of Management Journal, 37, 722-733.

Ullman, S.E. (2003) Social reactions to child sexual abuse disclosures: A critical review. Journal of Child Sexual Abuse, 12, 89-121.

RECEIVED: 08/18/04

REVISED: $10 / 18 / 04$

$11 / 19 / 04$

ACCEPTED: $11 / 22 / 04$ 